\title{
Exploring the potential benefits of digital health technology for the management of COPD: a qualitative study of patient perceptions
}

\author{
Patrick Slevin (1) 1 , Threase Kessie (1) ${ }^{1}$, John Cullen ${ }^{2,3}$, Marcus W. Butler ${ }^{4,5}$, \\ Seamas C. Donnelly ${ }^{2,3}$ and Brian Caulfield ${ }^{1}$
}

Affiliations: ${ }^{1}$ The Insight Centre for Data Analytics, University College Dublin, Dublin, Ireland. ${ }^{2}$ Tallaght University Hospital, Dublin, Ireland. ${ }^{3}$ Trinity College Dublin, Dublin, Ireland. ${ }^{4}$ University College Dublin, Dublin, Ireland. ${ }^{5}$ St Vincent's University Hospital, Dublin, Ireland.

Correspondence: Patrick Slevin, The Insight Centre for Data Analytics, University College Dublin, Dublin 4, Ireland. E-mail: patrick.slevindinsight-centre.org

ABSTRACT Engaging chronic obstructive pulmonary disease (COPD) patients to actively participate in self-management has proven difficult. Digital health technology (DHT) promises to facilitate a patientcentred care model for the management of COPD by empowering patients to self-manage effectively. However, digital health studies in COPD have yet to demonstrate significant patient outcomes, suggesting that this research has still to adequately address the needs of patients in the intervention development process. The current study explored COPD patients' perceptions of the potential benefits of DHT in the self-management and treatment of their disease.

A sample of convenience was chosen and participants $(n=30)$ were recruited from two Dublin university hospitals and each underwent a qualitative semi-structured interview. Thematic analysis of the data was completed using NVivo 12 software.

Six themes were identified: symptom management, anxiety management, interaction with physician, care management, personalising care and preventative intervention.

In our findings, patients reported a willingness to take a more active role in self-management using DHT. They perceived DHT potentially enhancing their self-management by improving self-efficacy and engagement and by supporting healthcare professionals to practise preventative care provision. The findings can be used to inform patient-centred COPD digital interventions for researchers and clinicians who wish to develop study aims that align with the needs and preferences of patients.

@ERSpublications

COPD patients perceive potential benefits accruing from using digital health technology in selfmanagement, including improved self-efficacy and perceived support for healthcare professionals to deliver preventative and personalised care http://bit.ly/2DhPMW7

Cite this article as: Slevin $\mathrm{P}$, Kessie T, Cullen J, et al. Exploring the potential benefits of digital health technology for the management of COPD: a qualitative study of patient perceptions. ERJ Open Res 2019; 5: 00239-2018 [https://doi.org/10.1183/23120541.00239-2018]. 


\section{Introduction}

By 2020, chronic obstructive pulmonary disease (COPD) is projected to be the third leading cause of death globally [1]. COPD adversely affects the quality of life of the patient, their family and caregivers, while also having a negative impact on their physical and social function [2]. Because COPD care is primarily undertaken by the patient in the community, self-management is a central component to managing the disease [3]. Self-management in COPD is linked with increased patient autonomy, reduction in hospitalisations and duration of exacerbations, decreased healthcare costs and improved health-related quality of life [4]. Yet, engaging patients to take an active participation in behaviours, activities and decision making related to self-management has proven difficult, with several barriers existing for patients and healthcare professionals (HCPs) [5-7].

Recently, there has been an emphasis placed on digital health technology (DHT), including remote monitoring devices, telehealth and telemonitoring platforms, to facilitate an integrated, patient-centred care model for the management of COPD [8-12]. These approaches focus on the tailoring of disease treatment and self-management to the needs of the patient by leveraging multimodal data sources, including those captured outside the clinic by the patient themselves in partnership with their care team [13]. The benefits of digitally captured health data such as activity and sleep data are gaining steady traction within healthcare policy [14-16], because of their potential to enhance patient self-management by increasing patient engagement and empowerment, to improve patient-clinician communication and to support clinicians with new forms of diagnostic and disease management information [17-20].

However, several studies and systematic reviews have been published regarding telemonitoring, mHealth and eHealth interventions in the management of COPD, with sparse evidence demonstrating positive improvements for patient self-management or treatment outcomes [21-25]. Issues with the development of self-management digital health interventions in COPD and for chronic diseases in general have been discussed $[22,26]$. Particularly, this work has highlighted digital interventions that set pre-determined research goals, such as reducing admissions or resource utilisation, which tend to offer "one-size-fits-all" solutions that elevate the importance of clinical outcomes, with the result that patients' needs and self-management practices are often ignored in the development stages of interventions [22, 26]. Moreover, although post-study evaluations of patient perceptions are frequently part of COPD digital health studies [27-29], the usefulness of these findings has been questioned, primarily because digital interventions find it difficult to reflect the reality of day-to-day healthcare for a patient due to the complexity of self-managing a disease with such a variable symptomology [22]. It is thus unsurprising that patient adoption and satisfaction issues are still frequently cited [23,30] and, although work is emerging that aims to gather patient perceptions of DHT pre-development [31], research remains sparse in this area.

There is a need, therefore, to re-engage with fundamental questions regarding the role envisioned for COPD patients in the development of digital health interventions. Specifically, it is worth asking whether COPD patients actually perceive potential benefits accruing from the use of DHT in the first instance. Exploring this avenue may help to identify future areas of digital health research that align more with the self-management and treatment needs of COPD patients to ensure that smoother adoption and implementation occurs $[22,23]$. Therefore, this study employed a qualitative study design to explore the following two research questions. 1) What are COPD patients' perceptions of the potential benefits of using DHT in the self-management of their disease? 2) What are their perceptions of how DHT may benefit how their disease management and treatment is delivered by their HCPs?

\section{Methods}

Study design

This study adopted a qualitative study design, namely one-to-one in-depth semi-structured interviewing of COPD patients.

\section{Recruitment and sample}

Patients were recruited from respiratory clinics at two university hospitals (Tallaght and St Vincent's, both in Dublin, Ireland). The patient characteristics are shown in table 1. For pragmatic reasons, a sample of convenience was chosen. Respiratory consultants (M.W. Butler and J. Cullen) identified potential participants at clinic, who were then invited to partake in the study. The inclusion criterion was a confirmed diagnosis of COPD following Global Initiative for Chronic Obstructive Lung Disease (GOLD) guidelines [32]. The GOLD stage classification of the patients in the sample is shown in table 2. Exclusion criteria were the existence of cognitive or psychotic disorders, or the existence of severe life-limiting comorbidities, for example lung cancer. Interested patients $(n=30)$ received an information leaflet and consent form and were given a 48 -h reflection period before being contacted by the researcher (P. Slevin) to confirm their participation. If they confirmed, a time and date convenient to the participant was 


\begin{tabular}{|c|c|}
\hline Characteristics & Data \\
\hline Male/female & $17 / 13$ \\
\hline Mean $\pm s D$ age years & $68.2 \pm 10.1$ \\
\hline \multicolumn{2}{|l|}{ Smoking history } \\
\hline Current smoker & 5 \\
\hline Ex-smoker & 25 \\
\hline \multicolumn{2}{|l|}{ Occupation status } \\
\hline Homemaker & 1 \\
\hline Carer's allowance recipient & 1 \\
\hline Retired & 20 \\
\hline Employed & 5 \\
\hline Unemployed & 3 \\
\hline \multicolumn{2}{|l|}{ Marital status } \\
\hline Married & 19 \\
\hline Widowed & 7 \\
\hline Single & 3 \\
\hline Separated & 1 \\
\hline \multicolumn{2}{|l|}{ Highest education level attained } \\
\hline Primary & 12 \\
\hline Secondary & 6 \\
\hline Third level and above & 12 \\
\hline \multicolumn{2}{|l|}{ Technology ${ }^{\pi}$} \\
\hline Smartphone & 16 \\
\hline Laptop and/or personal computer & 18 \\
\hline Both smartphone and laptop & 15 \\
\hline
\end{tabular}

scheduled for the interview. The number of patients who were approached but declined participation was not recorded. Written consent was obtained before each interview and all 30 interviews were conducted at patients' homes. Ethical approval was granted by University College Dublin, St Vincent's University Hospital and Tallaght University Hospital (all in Dublin).

\section{Procedure}

In-depth interviews were conducted by the first author (P. Slevin), who is an experienced qualitative researcher. A semi-structured interview topic guide (table 3) was used to frame the discussion. Questions explored patients' perceptions about 1) the potential benefit of using DHT in the self-management of their disease, and 2) how DHT may benefit how their disease management plan and treatment is delivered by their HCPs. The topic guide and open-ended questions allowed for new areas of conversation to emerge, which were then explored with the patient [33].

\section{Data analysis}

Interviews were audio-recorded with a Dictaphone, transcribed verbatim and anonymised. On average, interviews had a duration of 60-90 min. NVivo 12 software (QSR International Pty Ltd, Doncaster, Australia) was used to conduct thematic analysis of the transcripts. The interview topic guide was used to develop an initial draft codebook [34]. A sample of the transcripts was then independently analysed by

\section{TABLE 2 Chronic obstructive pulmonary disease severity classification}

\begin{tabular}{lccc} 
& GOLD stage & FEV $1 \%$ predicted & Patients n \\
\hline Mild & 1 & $\geqslant 80 \%$ & 2 \\
Moderate & 2 & $\geqslant 50 \%$ and $<80 \%$ & 16 \\
Severe & 3 & $\geqslant 30 \%$ and $<50 \%$ & 9 \\
Very severe & 4 & $<30 \%$ & 3 \\
Total & & 30 \\
GOLD: Global Initiative for Chronic Obstructive Lung Disease; FEV1: forced expiratory volume in 1 s.
\end{tabular}




\section{TABLE 3 Interview topic guide}

\begin{tabular}{|c|c|}
\hline Topic & Questions \\
\hline Demographics & $\begin{array}{l}\text { Age; marital status; occupation status; highest education attained; technology } \\
\text { (mobile or smartphone; personal computer; laptop); smoking history. }\end{array}$ \\
\hline Disease experience & $\begin{array}{l}\text { Can you discuss your experience of your COPD? } \\
\text { What is the role of family and friends when managing your COPD? } \\
\text { What types of self-management practices do you perform? } \\
\text { How do you feel about self-managing? } \\
\text { Can you discuss how you manage your symptoms? } \\
\text { Can you tell me about an exacerbation you had? } \\
\text { Can you discuss the last time you ended up in the GP clinic and/or hospital? }\end{array}$ \\
\hline $\begin{array}{l}\text { Healthcare } \\
\text { experience }\end{array}$ & $\begin{array}{l}\text { Can you tell me about the kinds of care you receive or have received for your } \\
\text { COPD? } \\
\text { How do you feel about the care you receive for your COPD? } \\
\text { Is the care you are receiving meeting your needs? }\end{array}$ \\
\hline $\begin{array}{l}\text { Health data and } \\
\text { DHT }\end{array}$ & $\begin{array}{l}\text { Do you record/log information about your health? If so, why/how? If not, why? } \\
\text { Do you think you could provide HCPs (e.g. GP or consultant) with more information } \\
\text { about your health day-to-day? } \\
\text { What types of information do you think your doctor should have about your health? } \\
\text { How would you feel about using a DHT (e.g. oximeter, COPD-related smartphone } \\
\text { app, spirometer, self-reported outcomes platform, etc.), to generate health } \\
\text { information/data about yourself? } \\
\text { What do you think about capturing information/data in the home? } \\
\text { How might collecting health information/data at home impact how you manage } \\
\text { your COPD? } \\
\text { Can you discuss why you might share information/data you collect with your HCP? } \\
\text { How do you think these types of information/data could be used by your HCP to } \\
\text { manage and treat your COPD? } \\
\text { Can you tell me how these types of data could be collected that would be suitable } \\
\text { for you and your needs? }\end{array}$ \\
\hline
\end{tabular}

COPD: chronic obstructive pulmonary disease; GP: general practitioner; DHT: digital health technology; HCP: healthcare professional.

P. Slevin and T. Kessie to iterate and finalise a comprehensive codebook $[35,36]$. Thematic analysis included reading each transcript closely, identifying patterns, assigning codes, and formulating themes and sub-themes from the data [37]. To ensure optimal analytical rigour was practised, the data were analysed and coded independently by the researchers (P. Slevin and T. Kessie), after which they were scrutinised, compared and discussed, to resolve any discrepancies [38]. When no new data, themes or relationships were being identified, data saturation was reached [39].

\section{Results}

All 30 patients completed an interview. The following themes emerged from analysis: 1) "benefits to patient self-management practices", which includes the three sub-themes "symptom management", "anxiety management" and "interaction with physician"; and 2) "benefits to HCP care provision", which includes the three sub-themes "care management", "personalising care" and "preventative intervention". The number of patients to influence each sub-theme with a response is presented in table 4 .

\section{Benefits to patient self-management practices Symptom management}

For many patients $(n=15)$, DHT had the potential to improve self-management skills such as symptom management. They felt that capturing health-related data could help with recognising and understanding their symptoms to better inform the modification of their self-management regime.

I'd say having that extra responsibility, you know, measuring those things, would give someone a more purposeful feeling with their COPD. Like, it's very hard to keep track of all the symptoms ... so it can be frustrating not knowing why am I out of breath? 
TABLE 4 Numbers of patients influencing sub-themes ${ }^{\#}$

Themes and sub-themes

Patients n

Benefits to patient self-management practices

Symptom management

Anxiety management

Interaction with physician

Benefits to HCP care provision

Care management

Personalising care

Preventative intervention

CP. healthcare professional. \#. total $n=30$.

I would like to know what is going on with me, I don't know the odd day why I am feeling lowly, or sleepy or out of breath so I can look at what I did today that was different and maybe change that.

Patient 101: age 62 years, GOLD stage 2, primary education level

It was also evident that patients felt that self-monitoring would encourage proactive responses to symptom change, leading to timelier decisions regarding seeking healthcare attention.

Well, checking the levels would help keep your mind in an active state, to react to something sinister, to keep going.

Patient 113: age 89 years, GOLD stage 2, PhD education level

It's about seeing them moments when I might not recover quickly, because they are the times I really need to act fast so that I don't get even worse.

Patient 106: age 67 years, GOLD stage 4, undergraduate education level

\section{Anxiety management}

Patients also spoke about the worry and anxiety associated with their disease $(n=13)$. For some, the worry of falling ill creates a source of apathy towards medication compliance and they see a potential for DHT to provide a reassuring status update that could ease such concerns.

I worry from time to time that I'm going to get worse quickly, so I suppose if I have something showing me that I am as healthy as I can be, that can only be a good thing, because worry puts a stress on the body and I mightn't be as all action, and then if you aren't bothered you might forget to take the inhalers.

Patient 104: age 73 years, GOLD stage 2, undergraduate education level

For others, a status update may help reduce symptom anxiety as they adjust to their new diagnosis.

Imagine after my diagnosis I'd be given a device to help me see the differences in a good day of breathing against a bad day of breathing? I know that would have eased the worry I had about every little change I was feeling. I'm sure plenty do panic at the slightest sign of being breathless.

Patient 132: age 61 years, GOLD stage 2, undergraduate education level

\section{Interaction with physician}

There was a general feeling of dissatisfaction expressed by patients regarding their consultation experience $(\mathrm{n}=11)$. However, patients felt that having their own data in a consultation would create meaningful, personalised and collaborative discussion, while others felt these data could more accurately describe their symptoms when they feel they cannot satisfactorily provide this type of information.

A lot of time is wasted in consultations talking about things I don't care about. If I was monitoring here at home then there would be plenty to talk about because the information collected would be about my COPD, about my symptoms, so that wouldn't be a waste of time, it'd be actually something to talk about and try to figure out, say if it was bad at the time.

Patient 127: age 57 years, GOLD stage 4, secondary education level

The type of monitoring we're talking about, it follows on into times when I am in the clinic with my GP [general practitioner], and he is asking me to describe how I have been feeling, that isn't easy to describe and 
then he will be asking me what were you doing that day, anything different? And I won't be able to remember, I've a terrible memory. It all gets vague from my side, and it is frustrating.

Patient 130: age 64 years, GOLD stage 1, undergraduate education level

\section{Benefits to HCP care provision}

Care management

Patients spoke about the benefits that could arise from sharing their digitally generated data with HCPs $(n=15)$. Some felt that their data could act as evidence of their compliance to self-management practices, while others commented that data presenting health status indicators may potentially reduce hospital visits by facilitating informed decision making.

I would feel they could see how the exercise doesn't change that much week to week, so they could be more confident that I am actually doing the right things.

Patient 121: age 72 years, GOLD stage 3, primary education level

If they were getting an idea for how my breathing is, say, if they knew that, "Yea, he's getting on well." Then they mightn't need to see me or that they could just tell me to head down to the GP instead.

Patient 117: age 64 years, GOLD stage 2, undergraduate education level

\section{Personalising care}

Patients also suggested that sharing their data could help with personalising their treatment through progress tracking, for instance, to optimise their medication $(n=12)$.

I'm sure hundreds of COPD patients are on the same inhalers, but they all can't work for each person the same, so if you are monitoring they might be able to tailor the inhalers for each person based on the information being gathered.

Patient 131: age 46 years, GOLD stage 2, undergraduate education level

So, imagine being a doctor and facing so many people every day, it must be impossible to know all of them? You couldn't know them too well or what goes on with them ... if in the future I am using the phone and answering questions there's a chance they would know more about me.

Patient 107: age 82 years, GOLD stage 2, apprenticeship education level

\section{Preventative intervention}

Patients articulated that HCPs could leverage the data captured to address the preventative care needs of individuals $(n=15)$, but this was primarily spoken about in the context of ill health. For example, patients commented on the potential of these data to instigate a timely intervention that could help classify the seriousness of their symptoms.

I think if they saw that information, that might tweak something with them or they could ask why I am feeling that way, say if I'm wheezing for a few days then it's clear I am not well, but if someone got onto me to say, we don't like the look of that, then I might take it more seriously.

Patient 105: age 65 years, GOLD stage 3, primary education level

Meanwhile, it was the benefit of capturing multiple health-related data points that interested other patients, who felt that having comprehensive indicators would streamline their access to healthcare services.

With my GP everything is done by appointment. If they say to me it's going to take 2 to 3 days before I can see you, I can become incredibly worse and if so what should we do now? So, I can say to the secretary, tell the doctor my oxygen level is 88 and it was like that last night and the morning before and tell him that my temperature is 101, so I really need to see them. No doctor can ignore them signs, so then I would be either brought in, or they could make the call to send me to hospital.

Patient 108: age 65 years, GOLD stage 3, secondary education level

\section{Discussion}

This study provides new insights about the perceptions of COPD patients regarding the potential benefits of using DHT in the self-management and treatment of their disease. Recognition and understanding of symptoms have been shown to affect COPD patients' ability to detect exacerbations [40] and, in this study, 
patients perceived that their capacity for symptom management could be improved by capturing data from DHT. Patients also expressed that using DHT could help to encourage proactive responses to symptom change, such as prompting more effective decision-making behaviours regarding accessing healthcare resources. By enhancing these skills and behaviours, the findings suggest that DHT could foster a greater sense of self-efficacy, referring to the patients' confidence in their ability to actively perform tasks associated with managing their disease $[41,42]$. It has been found that a decreased sense of self-efficacy can hinder the development and execution of fundamental self-management skills such as problem solving, self-tailoring, decision making and self-monitoring $[5,43]$. These findings support previous work that identified improved patient engagement and self-efficacy as an outcome of using data generated by DHT $[44,45]$. The findings of the current study reveal that patients perceive a role for data generated by DHT to reduce feelings of anxiety associated with their COPD. Anxiety is closely linked to the experience of deteriorating symptoms and a dyspnoea-related fear, which can impede the confidence of patients to self-manage, leading to non-adherence with treatment $[46,47]$. Interestingly, the opportunity to leverage digital health data to enhance patient self-efficacy could have a positive cascading effect on COPD-related anxiety.

Patients also spoke about how digital health data could help optimise the consultation experience by empowering them to partake in collaborative conversations concerning their self-management. For the patients, these data have the potential to ensure patient-centred communication and shared decision making, which are known to have a positive impact on patient satisfaction, adherence and selfmanagement outcomes $[48,49]$. Furthermore, patients felt their data could help with answering physician questions when, for instance, they were not satisfied they could provide an accurate account of symptoms from memory alone. This type of application could find traction in addressing recall issues experienced by patients. Prior research has found that COPD patients' recall of exacerbations over a 6-month period is overall inaccurate, which can lead to imprecise decisions regarding appropriate therapy [50, 51].

Additionally, the findings suggest that patients perceive several potential benefits accruing from sharing digital health data with HCPs. Particularly, findings relate to the opportunity for the capture of ongoing data to provide information about the patient's status during the inter-appointment period, where traditionally a knowledge gap exists [52]. It was felt that these data could act as a form of progress reporting that leverages indicators of health status, such as therapy compliance or symptom updates, to inform case management decisions including determining the necessity for hospital or GP visits. Moreover, the progress-reporting capability of the data generated by DHT was perceived as a possible mechanism for informing preventative interventions [53]. Patients felt that data would help HCPs identify suboptimal medication outcomes, which could facilitate the tailoring of inhalers based on personalised information. This finding speaks to the previous research investigating the self-management needs of COPD patients, which found participants expressing a desire for the provision of personalised care [54]. From the provider perspective, findings elsewhere have demonstrated that HCPs recognise that the provision of personalised care is a significant factor affecting the self-management behaviours of COPD patients [7].

Some studies have found the presence of consistently poor reporting behaviours among COPD patients, resulting in most exacerbations being unreported $[55,56]$, while other work has highlighted that $50 \%$ of asthma and COPD patients were found not to receive GP intervention prior to presenting to hospital [57]. Therefore, early detection of exacerbations and prompt intervention is preferred as they have been shown to reduce recovery time, improve health-related quality of life and reduce the risk of hospitalisation [55]. Such findings correspond to the types of self-management needs patients perceived digital health data helping to address in this study. Patients commented upon the potential for this data to stimulate collaboration with HCPs in the early detection of worsening symptoms. It was felt that data may encourage the timelier input of HCPs to help patients determine the seriousness of their symptoms and to guide appropriate action. Lastly, the opportunity for DHT to create a comprehensive set of meaningful, objective indicators was discussed. Patients suggested that data from DHT could better validate the urgency of their status to HCPs and, subsequently, streamline their access to healthcare services.

Using qualitative methodology, this study sought to gain an in-depth understanding of COPD patient perceptions regarding the potential benefits that DHT may have in the self-management and treatment of their disease. The rigorous approach employed in data collection and the use of NVivo12 software to support analysis offers strength to the findings. However, although heterogeneous, due to the relatively small sample size, the perceptions expressed may have limited generalisability. For example, although a sample of convenience was recruited, this cohort are well-educated, largely ex-smokers with a significant proportion having exposure to various technologies. These sample characteristics should not be ignored when considering the generalisability of the findings and future studies should include larger representative samples that might afford better understanding of the influence of factors such as digital 
literacy, education and age. That said, we did have a wide age range in our sample of convenience (46-89 years) and did not observe any marked effect of age in patient perceptions. Furthermore, because this research focuses on the potential benefits COPD patients perceive for the use of DHT, future research is needed to investigate patient perceptions of the barriers and facilitators for the use of these technologies. Understanding HCP perspectives will also be very important for determining the clinical impact DHT may have on routine care in COPD.

\section{Conclusion}

DHT is seen as an innovative solution for the provision of an integrated, patient-centred care model for the management of COPD. The findings of this study are encouraging, as they suggest that COPD patients are receptive to the role DHT can have in the management of their disease, with benefits being highlighted on several fronts. Patients perceive DHT enhancing their self-management by cultivating self-efficacy and engagement, empowering them to partake in collaborative discussions during consultations and supporting HCPs to foster preventative care-provision practices. These findings are important as they highlight that patients have unmet needs in several domains of self-management that are often not prioritised in COPD digital health studies where the aims and objectives are pre-determined. Therefore, the findings can be used to inform patient-centred COPD digital interventions for researchers and clinicians who wish to develop study aims that align with the needs and preferences of patients. However, the findings should be viewed as a stepping stone and should not be seen as a replacement for gaining a deeper appreciation for the needs of patients in the development stages of digital health interventions in COPD. Lastly, the findings are timely, as digital health in COPD has yet to demonstrate any significant improvements for patient outcomes, nor has it become part of routine care.

Acknowledgements: The authors would like to thank the patients who participated in the study for their time and openness.

Conflict of interest: None declared.

Support statement: This research was funded by Science Foundation Ireland (grant SFI/12/RC/2289). Funding information for this article has been deposited with the Crossref Funder Registry.

\section{References}

1 GBD 2015 Chronic Respiratory Disease Collaborators. Global, regional, and national deaths, prevalence, disability-adjusted life years, and years lived with disability for chronic obstructive pulmonary disease and asthma, 1990-2015: a systematic analysis for the Global Burden of Disease Study 2015. Lancet Respir Med 2017; 5: 691-706.

2 Barnett M. Chronic obstructive pulmonary disease: a phenomenological study of patients' experiences. J Clin Nurs 2005; 14: 805-812.

3 Pauwels RA. National and international guidelines for COPD: the need for evidence. Chest 2000; 117: Suppl. 2, 20S-22S.

4 Lenferink A, Brusse-Keizer M, van der Valk PD, et al. Self-management interventions including action plans for exacerbations versus usual care in patients with chronic obstructive pulmonary disease. Cochrane Database Syst Rev 2017; 8: CD011682.

5 Disler RT, Gallagher RD, Davidson PM. Factors influencing self-management in chronic obstructive pulmonary disease: an integrative review. Int J Nurs Stud 2012; 49: 230-242.

6 Zwerink M, Brusse-Keizer M, van der Valk PD, et al. Self management for patients with chronic obstructive pulmonary disease. Cochrane Database Syst Rev 2014; 3: CD002990.

7 Russell S, Ogunbayo OJ, Newham JJ, et al. Qualitative systematic review of barriers and facilitators to self-management of chronic obstructive pulmonary disease: views of patients and healthcare professionals. NPJ Prim Care Respir Med 2018; 28: 2.

8 Fairbrother P, Pinnock H, Hanley J, et al. Exploring telemonitoring and self-management by patients with chronic obstructive pulmonary disease: a qualitative study embedded in a randomized controlled trial. Patient Educ Couns 2013; 93: 403-410.

9 Blumenthal JA, Emery CF, Smith PJ, et al. The effects of a telehealth coping skills intervention on outcomes in chronic obstructive pulmonary disease: primary results from the INSPIRE-II study. Psychosom Med 2014; 76 581-592.

10 McDowell JE, McClean S, FitzGibbon F, et al. A randomised clinical trial of the effectiveness of home-based health care with telemonitoring in patients with COPD. J Telemed Telecare 2015; 21: 80-87.

11 Velardo C, Shah SA, Gibson O, et al. Digital health system for personalised COPD long-term management. BMC Med Inform Decis Mak 2017; 17: 19.

12 Lupton D. Digital Health: Critical and Cross-Disciplinary Perspectives. London, Routledge, 2017.

13 Swan M. Emerging patient-driven health care models: an examination of health social networks, consumer personalized medicine and quantified self-tracking. Int J Environ Res Public Health 2009; 6: 492-525.

14 National Information Board. Personalised health and care 2020. Using data and technology to transform outcomes for patients and citizens. A framework for action. Leeds, National Information Board, 2014. Available from: www.gov.uk/government/publications/personalised-health-and-care-2020

15 Australian Digital Health Agency. Australia's National Digital Health Strategy. Sydney, Australian Digital Health Agency, 2017. Available from: http://apo.org.au/node/182181 
16 US Food and Drug Administration. Digital Health Innovation Action Plan. Silver Spring, US Food and Drug Administration, 2017. Available from: www.fda.gov/MedicalDevices/DigitalHealth/default.htm

17 Ahern DK, Woods SS, Lightowler MC, et al. Promise of and potential for patient-facing technologies to enable meaningful use. Am J Prev Med 2011; 40: Suppl. 2, S162-S172.

18 Van Doornik W. Meaningful use of patient-generated data in EHRs. J AHIMA 2013; 84: 30-35.

19 Nundy S, Lu CY, Hogan P, et al. Using patient-generated health data from mobile technologies for diabetes self-management support: provider perspectives from an academic medical center. J Diabetes Sci Technol 2014; 8: $74-82$.

20 Chung AE, Sandler RS, Long MD, et al. Harnessing person-generated health data to accelerate patient-centered outcomes research: the Crohn's and Colitis Foundation of America PCORnet Patient Powered Research Network (CCFA Partners). J Am Med Inform Assoc 2016; 23: 485-490.

21 Free C, Phillips G, Galli L, et al. The effectiveness of mobile-health technology-based health behaviour change or disease management interventions for health care consumers: a systematic review. PLoS Med 2013; 10 : e1001362.

22 Brunton L, Bower P, Sanders C. The contradictions of telehealth user experience in chronic obstructive pulmonary disease (COPD): a qualitative meta-synthesis. PLoS One 2015; 10: e0139561.

23 McCabe C, McCann M, Brady AM. Computer and mobile technology interventions for self-management in chronic obstructive pulmonary disease. Cochrane Database Syst Rev 2017; 5: CD011425.

24 Vorrink S, Huisman C, Kort H, et al. Perceptions of patients with chronic obstructive pulmonary disease and their physiotherapists regarding the use of an eHealth intervention. JMIR Hum Factors 2017; 4: e20.

25 Bourbeau J, Farias R. Making sense of telemedicine in the management of COPD. Eur Respir J 2018; 51: 1800851.

26 Morton K, Dennison L, May C, et al. Using digital interventions for self-management of chronic physical health conditions: a meta-ethnography review of published studies. Patient Educ Couns 2017; 100: 616-635.

27 Fairbrother P, Pinnock H, Hanley J, et al. Continuity, but at what cost? The impact of telemonitoring COPD on continuities of care: a qualitative study. Prim Care Respir J 2012; 21: 322-328.

28 Hoaas H, Andreassen HK, Lien LA, et al. Adherence and factors affecting satisfaction in long-term telerehabilitation for patients with chronic obstructive pulmonary disease: a mixed methods study. BMC Med Inform Decis Mak 2016; 16: 26.

29 Williams V, Price J, Hardinge M, et al. Using a mobile health application to support self-management in COPD: a qualitative study. Br J Gen Pract 2014; 64: e392-e400.

30 Cruz J, Brooks D, Marques A. Home telemonitoring in COPD: a systematic review of methodologies and patients adherence. Int J Med Inform 2014; 83: 249-263.

31 Korpershoek YJG, Vervoort SCJM, Trappenburg JCA, et al. Perceptions of patients with chronic obstructive pulmonary disease and their health care providers towards using mHealth for self-management of exacerbations: a qualitative study. BMC Health Serv Res 2018; 18: 757.

32 Global Initiative for Chronic Obstructive Lung Disease (GOLD). Global Strategy for the Diagnosis, Management, and Prevention of Chronic Obstructive Pulmonary Disease. 2018. Available from: https://goldcopd.org/

33 Cohen D, Crabtree B. Qualitative Research Guidelines Project. Princeton, Robert Wood Johnson Foundation, 2006. www.qualres.org/

34 Saldaña J. The Coding Manual for Qualitative Researchers. 3rd Edn. Thousand Oaks, SAGE Publications, 2015.

35 DeCuir-Gunby JT, Marshall PL, McCulloch AW. Developing and using a codebook for the analysis of interview data: an example from a professional development research project. Field Methods 2011; 23: 136-155

36 Fereday J, Muir-Cochrane E. Demonstrating rigor using thematic analysis: a hybrid approach of inductive and deductive coding and theme development. Int J Qual Methods 2006; 5: 80-92.

37 Braun V, Clarke V. Using thematic analysis in psychology. Qual Res Psychol 2006; 3: 77-101.

38 Thomas DR. A general inductive approach for analyzing qualitative evaluation data. Am J Eval 2006; 27: 237-246.

39 Fusch PI, Ness LR. Are we there yet? Data saturation in qualitative research. Qual Rep 2015; 20: 1408-1416.

40 Warwick M, Gallagher R, Chenoweth L, et al. Self-management and symptom monitoring among older adults with chronic obstructive pulmonary disease. J Adv Nurs 2010; 66: 784-793.

41 Bourbeau J, Nault D, Dang-Tan T. Self-management and behaviour modification in COPD. Patient Educ Couns 2004; 52: 271-277.

42 Bandura A. Self-efficacy mechanism in human agency. Am Psychol 1982; 37: 122-147.

43 Lorig KR, Holman H. Self-management education: history, definition, outcomes, and mechanisms. Ann Behav Med 2003; 26: 1-7.

44 Hartzler AL, Taylor MN, Park A, et al. Leveraging cues from person-generated health data for peer matching in online communities. J Am Med Inform Assoc 2016; 23: 496-507.

45 Huniche L, Dinesen B, Nielsen C, et al. Patients' use of self-monitored readings for managing everyday life with COPD: a qualitative study. Telemed J E Health 2013; 19: 396-402.

46 McGeoch GR, Willsman KJ, Dowson CA, et al. Self-management plans in the primary care of patients with chronic obstructive pulmonary disease. Respirology 2006; 11: 611-618.

47 Pumar MI, Gray CR, Walsh JR, et al. Anxiety and depression - important psychological comorbidities of COPD J Thorac Dis 2014; 6: 1615-1631.

48 Charles C, Gafni A, Whelan T. Shared decision-making in the medical encounter: what does it mean? (Or it takes at least two to tango). Soc Sci Med 1997; 44: 681-692.

49 Levinson W, Roter DL, Mullooly JP, et al. Physician-patient communication. The relationship with malpractice claims among primary care physicians and surgeons. JAMA 1997; 277: 553-559.

50 Meek PM, Lareau SC, Anderson D. Memory for symptoms in COPD patients: how accurate are their reports? Eur Respir J 2001; 18: 474-481.

51 Frei A, Siebeling L, Wolters C, et al. The inaccuracy of patient recall for COPD exacerbation rate estimation and its implications: results from central adjudication. Chest 2016; 150: 860-868.

52 Wood WA, Bennett AV, Basch E. Emerging uses of patient generated health data in clinical research. Mol Oncol 2015; 9: 1018-1024.

53 Nittas V, Mütsch M, Ehrler F, et al. Electronic patient-generated health data to facilitate prevention and health promotion: a scoping review protocol. BMJ Open 2018; 8: e021245. 
54 Cicutto L, Brooks D, Henderson K. Self-care issues from the perspective of individuals with chronic obstructive pulmonary disease. Patient Educ Couns 2004; 55: 168-176.

55 Wilkinson TM, Donaldson GC, Hurst JR, et al. Early therapy improves outcomes of exacerbations of chronic obstructive pulmonary disease. Am J Respir Crit Care Med 2004; 169: 1298-1303.

56 Langsetmo L, Platt RW, Ernst P, et al. Underreporting exacerbation of chronic obstructive pulmonary disease in a longitudinal cohort. Am J Respir Crit Care Med 2008; 177: 396-401.

57 Naqvi $\mathrm{M}$, Khachi $\mathrm{H}$. The barriers to accessing primary care resulting in hospital presentation for exacerbation of asthma or chronic obstructive pulmonary disease in a large teaching hospital in London. Respir Med 2016; 117: $162-165$. 